\begin{tabular}{|c|c|}
\hline$S$ sciendo & 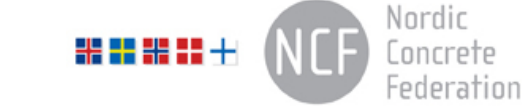 \\
\hline $\begin{array}{l}\text { (C) Article authors. This is an open access article distributed under } \\
\text { the Creative Commons Attribution-NonCommercial-NoDerivs } \\
\text { licens. (http://creaticecommons.org/licenses/by.nc-nd/3.0/). }\end{array}$ & $\begin{array}{l}\text { ISSN online } 2545-2819 \\
\text { ISSN print } \quad 0800-6377\end{array}$ \\
\hline DOI: $10.2478 /$ ncr-2021-0008 & $\begin{array}{r}\text { Received: March 31, } 2021 \\
\text { Revision received: June 15, } 2021 \\
\text { Accepted: June 16, } 2021\end{array}$ \\
\hline
\end{tabular}

\title{
Service Life of Concrete Pedestal without Air Entrainment
}

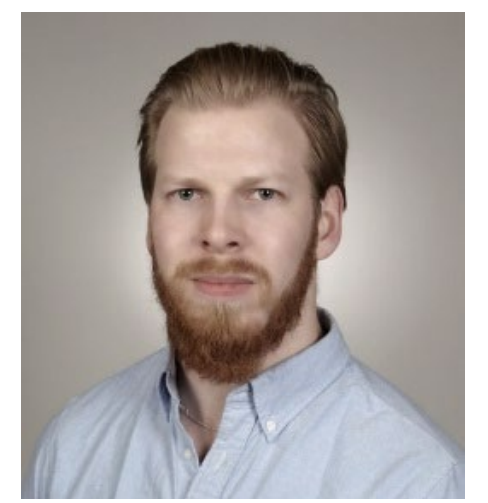

Niko Lindman

MSc

PhD student

Tampere University, Civil Engineering

niko.lindman@tuni.fi

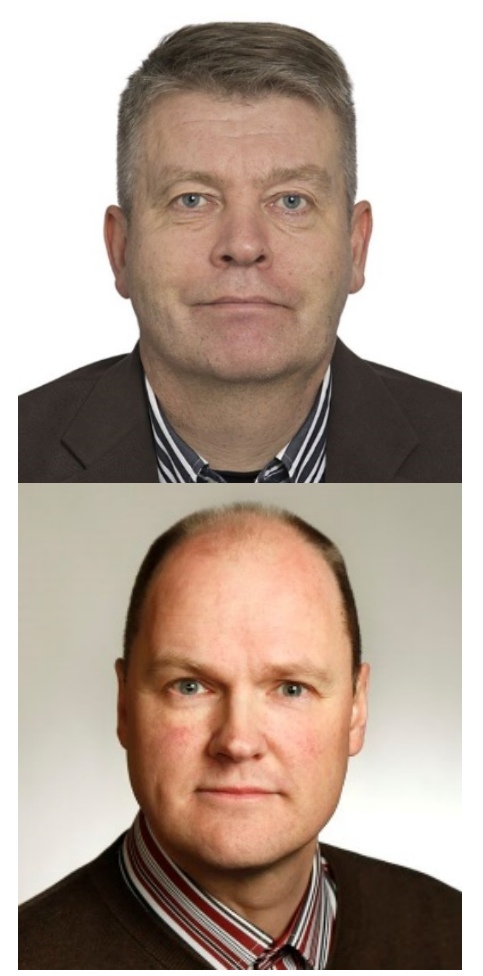

Jukka Kallio

MSc

Senior Design Director

Ramboll Finland Oy

jukka.kallio@ramboll.fi

Jukka Lahdensivu

DSc

Managing consultant

Ramboll Finland Oy

jukka.lahdensivu@ramboll.fi 


\begin{abstract}
Service life of nine wind power unit pedestals, which concrete grades between C45 and C55, were studied with four different service life models. The exact service life could be calculated only with two of them with the initial data.
\end{abstract}

The service life models that were used in calculations:

- Factor method

- Deterioration and service life prediction of concrete subjected to freeze-thaw cycles in Na2SO4 Solution -method

Service life models that were considered only at theoretical level:

- FIB Bulletin 34 - Model Code for Service Life Design, and

- An equation for determining freeze-thaw fatigue damage in concrete and a model for predicting the service life.

The latter two methods are more theoretical, and they require laboratory tests to obtain more information before the calculations can be properly executed.

This article concludes that damage to concrete due to freeze-thaw cracking is still poorly known and a sufficiently accurate service life model has not yet been developed for its computational modeling. Therefore, there is a need to develop a service life model suitable for Finnish climate and concrete grades, which could be used for estimating the damage rate of an existing concrete structure.

Key words: Wind power, concrete, air entrainment, service life

1.

INTRODUCTION

1.1

General

In Finland and other Nordic countries freeze-thaw resistance of concrete structures exposed to outdoor climate is ensured with air-entrainment agents in the concrete mixture. In Finland airentrainment has been used regularly since 1980's, but it has failed in many cases. During 2017 and 2018 there was a concrete crisis in Finland. Air-entrainment was added too much in fresh concrete causing too much porosity in concrete and one consequence was that compressive strength remained too low level. For that reason, in the structures, where concrete grade is relatively high, service life less than 50 years and wetting of concrete from wind driven rain slight, concrete is made without air-entrainment.

However, despite the lack of air-entrainment in the concrete, freeze-thaw damage in concrete proceed relatively slow. Visual damage of concrete façades and balconies has a strong correlation with precipitation, wind directions during the rain and freeze-thaw cycles directly after the rain events $[1,2]$. According to Finnish Meteorological Institute there are approximately 90 freezingand-thawing cycles in a year. Variation is large because of the yearly changes in the local weather 
conditions. The number of the freezing-and-thawing cycles, where precipitation has been first rain or sleet and then the temperature has dropped below $-5^{\circ} \mathrm{C}$, is approximately 15 per year [3]. In thin-section analysis of exposed aggregate concrete facades, concrete grade K25-2 (C20/25), incipient freeze-thaw damage starts to happen after 307 freezing-and-thawing cycles. This means 22 - 24 years in exposure to outdoor conditions. In balcony slabs, where the freeze-thaw stress is higher than in facades (exposure class XF3), the concrete grade generally used is at least K30-2 $(\mathrm{C} 25 / 30)$ since 1960 's. In these balcony slabs there isn't detected any starting or advanced freezethaw damage [1].

This article summarizes critically different models currently used to determine the service life of concrete models that have been used to attempt to calculate the estimated service life of nine wind power unit pedestals. In addition, service life models and their practicality have been compared on a theoretical level.

\section{Freeze-thaw attack on concrete}

More than 15 different theories or explanations for freeze-thaw attack on porous materials have been presented [4]. That proves that frost attack is a complex process and freeze-thaw damage can take many different forms [5].

Probably the most widely known frost damage theory is the hydraulic pressure theory by Powers published in 1949. Accordingly, damage occurs as freezing water expands creating hydraulic pressure within the pore structure of a porous material. The pressure is created when part of the water in a capillary pore freezes and expands forcing thereby the unfrozen water out of the pore. The migration of water causes localised internal tensions in the material whereby its strength may fail resulting in cracking [6]. The theory of hydraulic pressure is considered valid nowadays only in highly saturated conditions.

The theory of volume changes in microscopic ice crystals was developed to complete the hydraulic pressure theory. During the freezing process, small ice crystals tend to grow in capillary pores. If there is not enough empty space for the growing ice crystals, they will build pressure in the pore structure and may lead to its cracking. The growth of microscopic ice crystals will continue despite the lowering of temperature during the freezing phase [6].

Litvan noticed in the beginning of the 1970's that the water in the pore structure of a porous material does not freeze immediately as temperature drops below $0^{\circ} \mathrm{C}$. Freezing happens first in large capillary and compaction pores. Amongst other things, the salts that are dissolved into the pore water of the concrete lower the freezing point to typically somewhere between -3 and $-5^{\circ} \mathrm{C}$ [6]. In small gel pores water begins to freeze when the temperature is about -15 to $-20^{\circ} \mathrm{C}$. The unfrozen pore water is thus supercooled, which tends to cause drying of the paste because the saturation pressure of supercooled water is higher than that of ice. According to Litvan, mechanical damage happens when moisture transfer cannot occur in an orderly manner, i.e. when the rate of freezing is too high, or the distance that water must travel to reach an external surface and freeze is too long [6].

The theory of the critical degree of water saturation was developed by Fagerlund in the early 1970's [5]. It suggests that there is a critical degree of water saturation above which porous and brittle material gets damaged while freezing. If actual water saturation is below critical, no damage takes place during freezing. 
Increasing temperature on the façade or other concrete structure also increases the temperature of ice in the pore structure. When temperature decreases, the ice in the pore structure first shrinks allowing supercooled pore water to flow by capillary action to "new" empty spaces in pores where it freezes rapidly. When temperature increases, the ice will need more space than before. This causes significant hydraulic pressure on the pore structure [7]. The thermal expansion coefficient of ice is $50 \times 10^{-6}$ per $\mathrm{K}$ or 3.5 to 10 times higher than the temperature expansion coefficient of concrete $[8,9]$. The temperature expansion coefficient of concrete varies a lot and is influenced by the two main constituents of concrete: hydrated cement paste and aggregate [10].

\section{ABOUT SERVICE LIFE MODELS}

The service life of reinforced concrete structures has been a topic for intense international research for more than 20 years. Since the late 1990's durability design has been addressed by several international projects/committees: RILEM Technical Committee 130-CSL on performance-based approach to durability design of concrete structures [11]; EU-LIFECON Project addressing the life cycle management of concrete infrastructures for improved sustainability; EU-DURACETE on the probabilistic performance-based durability design of concrete structures. These projects laid the foundations for the fib Model Code for service life design [12] which has since become one of the most widely used modelling approaches. Current models typically address one degradation mechanism at a time, and do not consider the possible synergetic effect of combined degradation modelling [13].

For concrete building façades, especially in Nordic climate, degradation is mainly inherent from the effects of freeze-thaw coupled with the corrosion problems in carbonated concrete [1]. The effect of climate change is unclear on both phenomena though some advances have been made in the study of the effects of climate change on carbonation. On freeze-thaw effect, the research is still lacking. Many different theories or explanations for freeze-thaw damage of porous materials have been presented [14] proving that freeze-thaw damage is a complex process and freeze-thaw damage can take many different forms [15]. For the modelling of freeze-thaw damage, significant contributions exist. However, models have not yet evolved sufficiently to enable a performancebased approach $[12,15,16,17,18,19]$.

\section{1}

\section{Factor method}

The most used way in Finland to estimate the service life of concrete structure is so called factor method which is described in Concrete codes - by65 [20] and it has been available since 2004, when the first version was published. Factor method is originally defined in ISO 15686 [21] standards, where the target service life of the structure is set by the client, typically $50-200$ years. The estimated service life is calculated separately to each structure in different exposure classes for two degradation mechanisms (freeze-thaw and carbonation induced corrosion). Eventually shortest service life obtained is decisive. The factor method is based on the use of a reference service life multiplied by seven numerical coefficients that take into account different service life factors. The general formula for the factor method is as follows:

$$
t_{\mathrm{ESL}}=t_{\mathrm{RSL}} * A * B * C * D * E * F * G
$$


where $t_{\mathrm{ESL}}$ is the estimated service life of the structure, $t_{\mathrm{RSL}}$ is the reference service life and the parameters $A-G$ are service life factors [20]. Definitions for factors $A-G$ are shown in Table 1 [21].

Table 1 -Definition for the service life factors $A-G$ [21].

\begin{tabular}{lll}
\hline Factor & Factor category & Description \\
\hline A & $\begin{array}{l}\text { Inherent performance } \\
\text { level }\end{array}$ & $\begin{array}{l}\text { Grade of the component in the time on delivery. } \\
\text { Durability performance of the material. }\end{array}$ \\
\hline B & Design level & $\begin{array}{l}\text { Reflects the component's installation in the building. The design choices } \\
\text { made can provide shelter and protection from degradation agents. }\end{array}$ \\
\hline $\mathrm{C}$ & Work execution level & $\begin{array}{l}\text { Considers the level of skill and control in site work. Storage, protection } \\
\text { during installation, ease of installation, manufacturer's recommendations, } \\
\text { etc. }\end{array}$ \\
\hline $\mathrm{D}$ & Indoor environment & Considers the exposure of component to indoor degradation agents. \\
\hline $\mathrm{E}$ & Outdoor environment & $\begin{array}{l}\text { Considers the exposure of component to outdoor degradation agents. The } \\
\text { effect of weather conditions and microclimate surrounding the component } \\
\text { should be taken into account. }\end{array}$ \\
\hline $\mathrm{F}$ & Usage conditions & Takes into account the wear that occurs during the use of the building. \\
\hline $\mathrm{G}$ & Maintenance level & $\begin{array}{l}\text { Represents the level of maintenance of the component. Includes cleaning, } \\
\text { maintenance, repair, replacement, among other activities and how } \\
\text { accessible the component is for maintenance. }\end{array}$ \\
& &
\end{tabular}

Parameter $E$ can be divided into sub-factors $E_{1}$ (exposure class), $E_{2}$ (structure orientation) and $E_{3}$ (geographical location). Values for each parameter can be found from tables presented in Concrete codes - by65. The factor having the biggest effect on estimated service life is factor $A$ (material properties), which considers concretes $\mathrm{w} / \mathrm{c}$ ratio, maximum aggregate size and air content of fresh concrete when calculating service life related with freeze-thaw. When estimating service life related to corrosion of reinforcement the factor $A$ considers the concrete grade, type of cement and/or binder and the air content of fresh concrete. The other factors are basically based on computer simulations and are therefore made almost 20 years ago. Regarding climate change, for example, the calculations need to be updated $[22,23]$.

\section{Deterioration and service life prediction of concrete subjected to freeze-thaw cycles in Na2SO4 Solution}

Li et al. [24] present a service life calculation model for a structure determined on the basis of laboratory tests, which is based on the reduction of the dynamic modulus of elasticity of concrete caused by freeze-thaw cycles as well as environmental conditions. The formula for the service life $T$ (in years) of the structure is as follows:

$$
T=\frac{B * N}{k * M}
$$

where $B$ is the coefficient of the freeze-thaw test, which relates the rapid freeze-thaw cycle performed under laboratory conditions to the freeze-thaw cycle in the natural environment. Generally, this factor is set to 12 , that is, the number that one rapid freeze-thaw cycle produced in the laboratory corresponds to under natural conditions. The parameter $k$ in Eq. 2 is the safety factor for the design of the concrete structure, which can be compared with the partial safety factors defined by the Eurocode, as it is generally set to 1.5 . $N$ is the maximum number of freeze- 
thaw cycles that the concrete quality can withstand, and $M$ is the average annual number of freezethaw cycles to which the concrete structure is exposed in the natural environment [24].

A freeze-thaw cycle means that the structure has once been exposed to freezing, i.e. the temperature has dropped below $0^{\circ} \mathrm{C}$ and then melted, i.e. the temperature has risen again above $0^{\circ} \mathrm{C}$. The annual number of freeze-thaw cycles is recorded by region, and thus the average annual number of freeze-thaw cycles $M$ can be applied to a given region. In Finland, the regions can be roughly divided into coastal, central and northern Finland. The measurement sites mentioned above are in Helsinki-Vantaa, Jyväskylä and Rovaniemi [25].

The maximum number of freeze-thaw cycles $(N)$ is a factor depending on the concrete grade. Shang et al. [26] present a study in which this factor has been studied with different concrete grades and air volume concentrations. The idea of the experiment performed in the laboratory was to expose the cube-shaped sample to rapid freeze-thaw cycles, after which the compressive strength of the sample is measured after a certain number of cycles. This creates a connection between the number of freeze-thaw cycles and the decrease in compressive strength for a given concrete grade [26]. According to the Finnish freeze-thaw stress test standard, concrete is considered as damaged when the compressive strength of the concrete has decreased by $33 \%$ from the original strength [27].

Compressive strength of concrete is not the best indicator for cracking of concrete caused by freeze-thaw attack because when the concrete is subjected to compression, it closes the cracks. Even relatively severe cracked concrete can have sufficient high compression strength while tensile strength shows clear damage in the concrete [28]. Tensile strength is therefore much better indicator for cracking of concrete caused by freeze-thaw attack or alkali-silica reaction. However, compression strength and tensile strength of concrete has a connection. When compression strength increases also tensile strength will increase. The increase of tensile strength is not linear. In concrete grade $\mathrm{C} 20 / 25$ tensile strength is approximately $2 \mathrm{MPa}$, but concrete grade $\mathrm{C} 60 / 67$ tensile strength in approximately $5 \mathrm{MPa}[10]$.

\subsection{FIB Bulletin 34 - Model Code for Service Life Design (MC-SLD)}

MC-SLD is based on the concrete's critical humidity, based on which the effect of the structure's service life on the structure's service life is determined. MC-SLD is based on the following formula:

$$
g\left(S_{C R}, S_{A C T}\left(t<t_{S L}\right)\right)=S_{C R}-S_{A C T}\left(t<t_{S L}\right)
$$

where $S_{\mathrm{CR}}$ is the critical degree of moisture saturation, $S_{\mathrm{ACT}}$ is the actual degree of moisture saturation at time $t$, and $t_{\mathrm{SL}}$ is the design life of the structure in years, which is determined by the intended use of the object [29].

\section{An equation for determining freeze-thaw fatigue damage in concrete and a model for predicting the service life}

One service life model presented in Yu et al's study [30] is based on the theory that water entering the internal capillary pores of concrete expands as it freezes. Regarding the service life calculation, 
it is characteristic of the model to study the deterioration of the dynamic modulus of elasticity and tensile strength of the concrete grade used as the number of freeze-thaw cycles progresses. The attenuation of the dynamic modulus of elasticity is taken into account by the material parameter $\beta$, which has the following formula:

$$
\beta=\frac{D_{\mathrm{N}-1}}{\log N} \approx \frac{D_{\mathrm{N}}}{\log N}
$$

where $D_{N}$ represents the percentage loss of the dynamic modulus of elasticity. The idea of the model is to study the maximum loss of the dynamic modulus of elasticity, after which the concrete can no longer withstand the freeze-thaw stress. According to the general Chinese standard $D_{N}=$ 0.4 , but in the corresponding case in Finland the value $D_{N}=0.25$ is used according to the standard SFS 5447 [31]. In practice, therefore, this is the threshold at which the value of the dynamic modulus of elasticity of the concrete is $75 \%$ of what it was before the start of the freeze-thaw stress. Correspondingly, the parameter $N$ denotes the number of freeze-thaw cycles which causes the loss of this $25 \%$ dynamic modulus of elasticity [30].

\section{RESEARCH DATA AND METHODS}

The presented service life models were tried to be applied for calculating the estimated service life for nine actual wind power plant pedestals. The initial data obtained from the pedestals are shown in Table 2.

Table 2 - The initial data obtained from the case pedestals.

\begin{tabular}{lllllll}
\hline Pedestal & Location & $\begin{array}{l}\text { Concrete } \\
\text { grade }\end{array}$ & Exposure class & Design service life [yr.] & w/c ratio & air \% \\
\hline 1 & Coast & C45/55 & XF3 & 50 & 0.39 & 2 \\
2 & Central Finland & C55/67 & XF3 & 50 & 0.34 & 2 \\
3 & Coast & C55/67 & XF3 & 50 & 0.38 & 2 \\
4 & Northern Finland & C50/60 & XF3 & 50 & 0.40 & 2 \\
5 & Coast & C55/67 & XF3 & 50 & 0.41 & 2 \\
6 & Central Finland & C55/67 & XF3 & 50 & 0.38 & 2 \\
7 & Central Finland & C50/60 & XF3 & 50 & 0.38 & 2 \\
8 & Central Finland & C55/67 & XF3 & 50 & 0.38 & 2 \\
9 & Central Finland & C55/67 & XF3 & 50 & 0.38 & 2 \\
\hline
\end{tabular}

Based on the available data from the pedestals, it was possible to calculate the estimated service lives with the factor method and the Deterioration and service life prediction of concrete subjected to freeze-thaw cycles in Na2SO4 solution method.

\section{RESULTS}

The service lives obtained with factor method is shown in Table 3 and Deterioration and service life prediction of concrete subjected to freeze-thaw cycles in Na2SO4 solution method in Table 4. 
Table 3 - Estimated service lives, factor method. Factors according to Concrete codes - by65 [20].

\begin{tabular}{c|ccccccccccc}
\hline & \multicolumn{10}{|c}{ Factor } \\
Pedestal & $t_{\text {RSL }}$ & $A$ & $B$ & $C$ & $D$ & $E_{1}$ & $E_{2}$ & $E_{3}$ & $F$ & $G$ & $t_{\text {ESL }}$ \\
\hline 1 & 50 & 1.40 & 1.3 & 1.0 & - & 0.67 & 1.0 & 1.0 & - & 0.7 & 43 \\
2 & 50 & 2.32 & 1.3 & 1.0 & - & 0.67 & 1.0 & 1.1 & - & 0.7 & 78 \\
3 & 50 & 1.52 & 1.3 & 1.0 & - & 0.67 & 1.0 & 1.0 & - & 0.7 & 46 \\
4 & 50 & 1.30 & 1.3 & 1.0 & - & 0.67 & 1.2 & 1.0 & - & 0.7 & 48 \\
5 & 50 & 1.22 & 1.3 & 1.0 & - & 0.67 & 1.0 & 1.0 & - & 0.7 & 37 \\
6 & 50 & 1.52 & 1.3 & 1.0 & - & 0.67 & 1.1 & 1.0 & - & 0.7 & 51 \\
7 & 50 & 1.52 & 1.3 & 1.0 & - & 0.67 & 1.1 & 1.0 & - & 0.7 & 51 \\
8 & 50 & 1.52 & 1.3 & 1.0 & - & 0.67 & 1.0 & 1.1 & - & 0.7 & 51 \\
9 & 50 & 1.52 & 1.3 & 1.0 & - & 0.67 & 1.0 & 1.1 & - & 0.7 & 51 \\
\hline
\end{tabular}

\begin{tabular}{ll}
\hline Notices: & \\
B: & Massive structure, no coating \\
C: & Concrete curing according by65 \\
D: & Structure is outside \\
F: & No separate service exposure \\
G: & Inspection time is rarely
\end{tabular}

Table 4 - Estimated service life, Deterioration and service life prediction of concrete subjected to freeze-thaw cycles in Na2SO4 solution method.

\begin{tabular}{c|ccccc}
\hline & \multicolumn{2}{c}{ Factor } & $k$ & \\
\hline Pedestal & $B$ & $N$ & $k$ & 26 & 123 \\
2 & 12 & 400 & 1.5 & 27 & 119 \\
3 & 12 & 400 & 1.5 & 26 & 123 \\
4 & 12 & 400 & 1.5 & 20 & 160 \\
5 & 12 & 400 & 1.5 & 26 & 123 \\
6 & 12 & 400 & 1.5 & 27 & 119 \\
7 & 12 & 400 & 1.5 & 27 & 119 \\
8 & 12 & 400 & 1.5 & 27 & 119 \\
9 & 12 & 400 & 1.5 & 27 & 119 \\
\hline
\end{tabular}

Parameter $N$, i.e., the number of freeze-thaw cycles for a particular concrete grade, was determined from Table 5. In Shang et al.'s study [26], values have been determined only for certain concrete grades, so the values for concrete grade $\mathrm{C} 45$ were interpolated (linear interpolation) and values for concrete grade C55 were extrapolated (linear extrapolation).

Table 5 - Parameter $N[26,30]$.

\begin{tabular}{c|cccccccc}
\hline \multirow{2}{*}{$\begin{array}{c}\text { Concrete } \\
\text { grade }\end{array}$} & 0 & 50 & 100 & 150 & 200 & 300 & 350 & 400 \\
\cline { 2 - 9 } & \multicolumn{8}{c}{ Pumber of fast freeze thaw-cycles } \\
\hline C55** & 62.6 & 59.8 & 61.4 & 58.9 & 61.5 & 54.7 & 52.4 & 45.8 \\
C50 & 56.0 & 54.1 & 54.2 & 52.3 & 53.6 & 47.9 & 45.8 & 38.6 \\
C45* & 49.4 & 48.4 & 47.0 & 45.7 & 45.7 & 41.2 & 39.2 & 31.9 \\
C40 & 42.8 & 42.7 & 39.9 & 39.1 & 37.8 & 34.4 & 32.6 & 24.9 \\
C30 & 34.2 & 33.4 & 31.7 & 27.6 & 26.4 & 21.1 & 19.1 & 16.2 \\
C25 & 28.7 & 27.0 & 26.3 & 22.3 & 20.8 & 14.5 & - & - \\
C20 & 23.6 & 23.2 & 22.1 & 20.8 & 17.6 & 10.2 & - & - \\
\hline
\end{tabular}

*interpolated **extrapolated 
The values of the parameter $M$ are presented in Figure 1, which shows the number of annual freeze-thaw cycles in different regions in Finland.

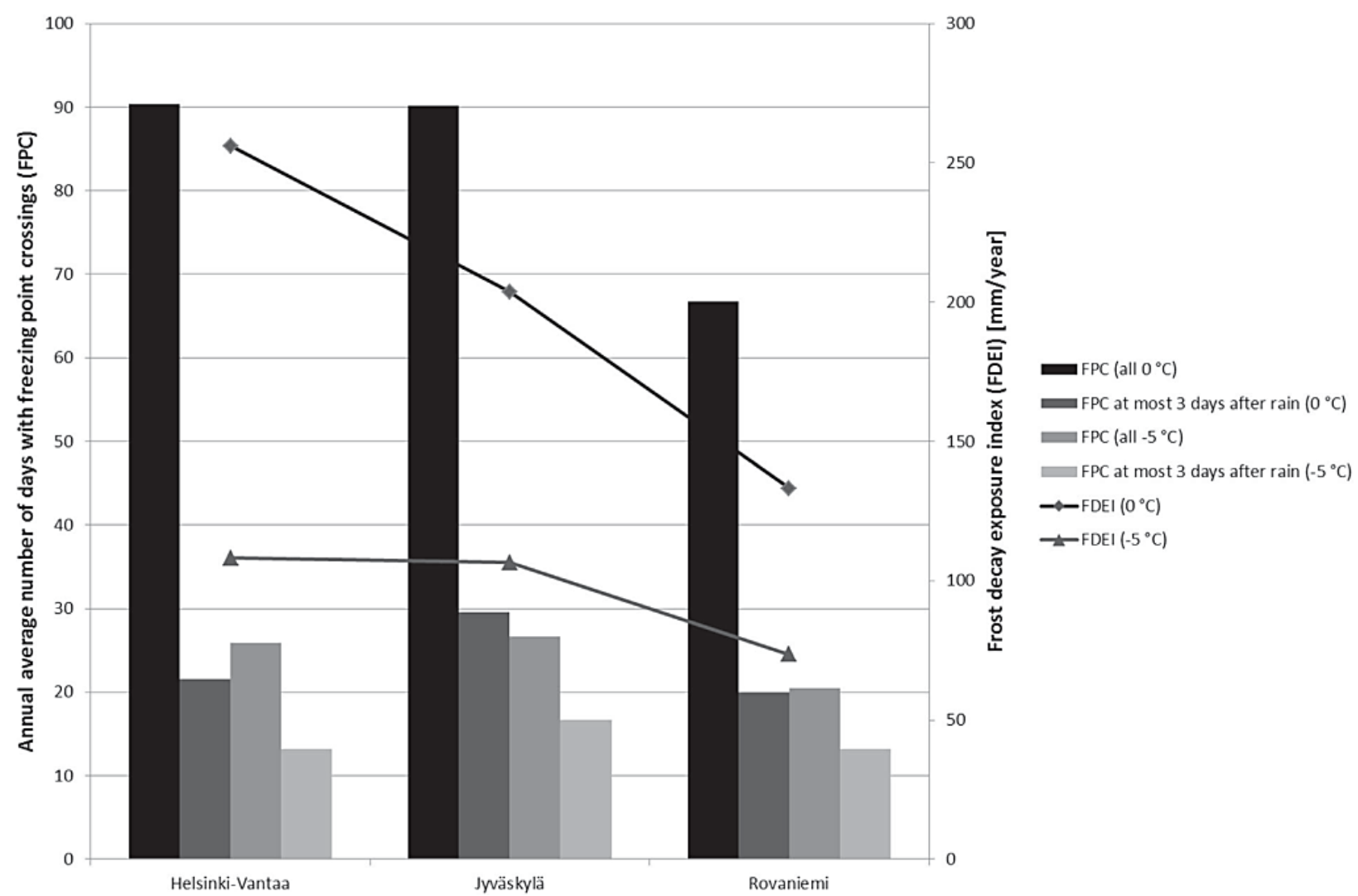

Figure 1 - Frost decay exposure index for different geographical locations in southern coastal are (Helsinki-Vantaa), inland (Jyväskylä) and Lapland (Rovaniemi) presented as lines. The annual freeze-thaw cycles with temperature crossings under $0^{\circ} \mathrm{C}$ and $-5^{\circ} \mathrm{C}$ as well as the situation when it has rained within 3 days of freezing occurring are indicated by the columns [25].

\section{DISCUSSION}

With the initial data available from the pedestals, the service life could be calculated by the factor method and Deterioration and service life prediction of concrete subjected to freeze-thaw cycles in Na2SO4 Solution -method. Other methods presented require laboratory tests to obtain more information before the calculations can be properly executed. The service lives of pedestals calculated with factor method and Deterioration and service life prediction of concrete subjected to freeze-thaw cycles in Na2SO4 Solution method are presented in Table 6. 
Table 6-Difference in calculated service life of pedestals with different methods and freezethaw cycles.

\begin{tabular}{|c|c|c|c|c|c|}
\hline \multirow[b]{2}{*}{ Pedestal } & \multirow{2}{*}{$\begin{array}{l}\text { Factor method } \\
\text { tESL [years] }\end{array}$} & \multicolumn{2}{|c|}{$\begin{array}{l}\text { Service life model } \\
\text { Deterioration and service life prediction of } \\
\text { concrete subjected to freeze-thaw cycles in } \\
\text { Na2SO4 solution method }\end{array}$} & \multicolumn{2}{|c|}{$\begin{array}{l}\text { Difference } \\
\text { compared to factor method }\end{array}$} \\
\hline & & $\begin{array}{l}\text { Freeze-thaw } \\
\text { cycles } 0^{\circ} \mathrm{C} \\
\boldsymbol{t}_{\text {ESL }} \text { [years] }\end{array}$ & $\begin{array}{l}\text { Freeze-thaw } \\
\text { cycles }-5^{\circ} \mathrm{C} \\
\boldsymbol{t}_{\mathrm{ESL}} \text { [years] }\end{array}$ & $\begin{array}{l}\text { Freeze-thaw } \\
\text { cycles } 0^{\circ} \mathrm{C} \\
\text { [years] }\end{array}$ & $\begin{array}{l}\text { Freeze-thaw } \\
\text { cycles }-5^{\circ} \mathrm{C} \\
\text { [years] }\end{array}$ \\
\hline 1 & 43 & 36 & 123 & -7 & 80 \\
\hline 2 & 78 & 36 & 119 & -42 & 41 \\
\hline 3 & 46 & 36 & 123 & -7 & 77 \\
\hline 4 & 48 & 47 & 160 & -1 & 112 \\
\hline 5 & 37 & 36 & 123 & -1 & 86 \\
\hline 6 & 51 & 36 & 119 & -15 & 68 \\
\hline 7 & 51 & 36 & 119 & -15 & 68 \\
\hline 8 & 51 & 36 & 119 & -15 & 68 \\
\hline 9 & 51 & 36 & 119 & -15 & 68 \\
\hline
\end{tabular}

5.1

\section{Deterioration and service life prediction of concrete subjected to freeze-thaw cycles in $\mathrm{Na} 2 \mathrm{SO} 4$ Solution}

As can be seen from Table 6, factor method gives the estimated service life for pedestals between 37 and 78 years. The Deterioration and service life prediction of concrete subjected to freezethaw cycles in Na2SO4 solution method gives different service life depending on the used criteria of freeze-thaw cycles. By using annual freeze-thaw cycles where temperature goes below $-5^{\circ} \mathrm{C}$ and then back above $0^{\circ} \mathrm{C}$, the service life is between 119 and 160 years. Using of this temperature criterion is supported by the fact that porewater in concrete freezes mostly when temperature goes below -3 to $-5^{\circ} \mathrm{C}[6]$. And then the difference in estimated service lives between those two models varied between 41 and 112 years. However, by using the annual freeze-thaw cycles where temperature goes just below $0^{\circ} \mathrm{C}$ and back, the service life is 36 or 47 years. These service lives are much closer ones calculated with the factor method. The difference is between 1 and 42 years.

The most determinant factor recognized when using Deterioration and service life prediction of concrete subjected to freeze-thaw cycles in Na2SO4 solution method is factor $M$, which stands for average annual number of freeze-thaw cycles but also geographical location of pedestal. Depending on where the studied pedestal is geographically located, the $M$ factor can vary approximately $25 \%$, which affects directly to the service life obtained. With such high concrete grades used in this study, the factor $N$ seems to be quite high (over 400) in any case. 


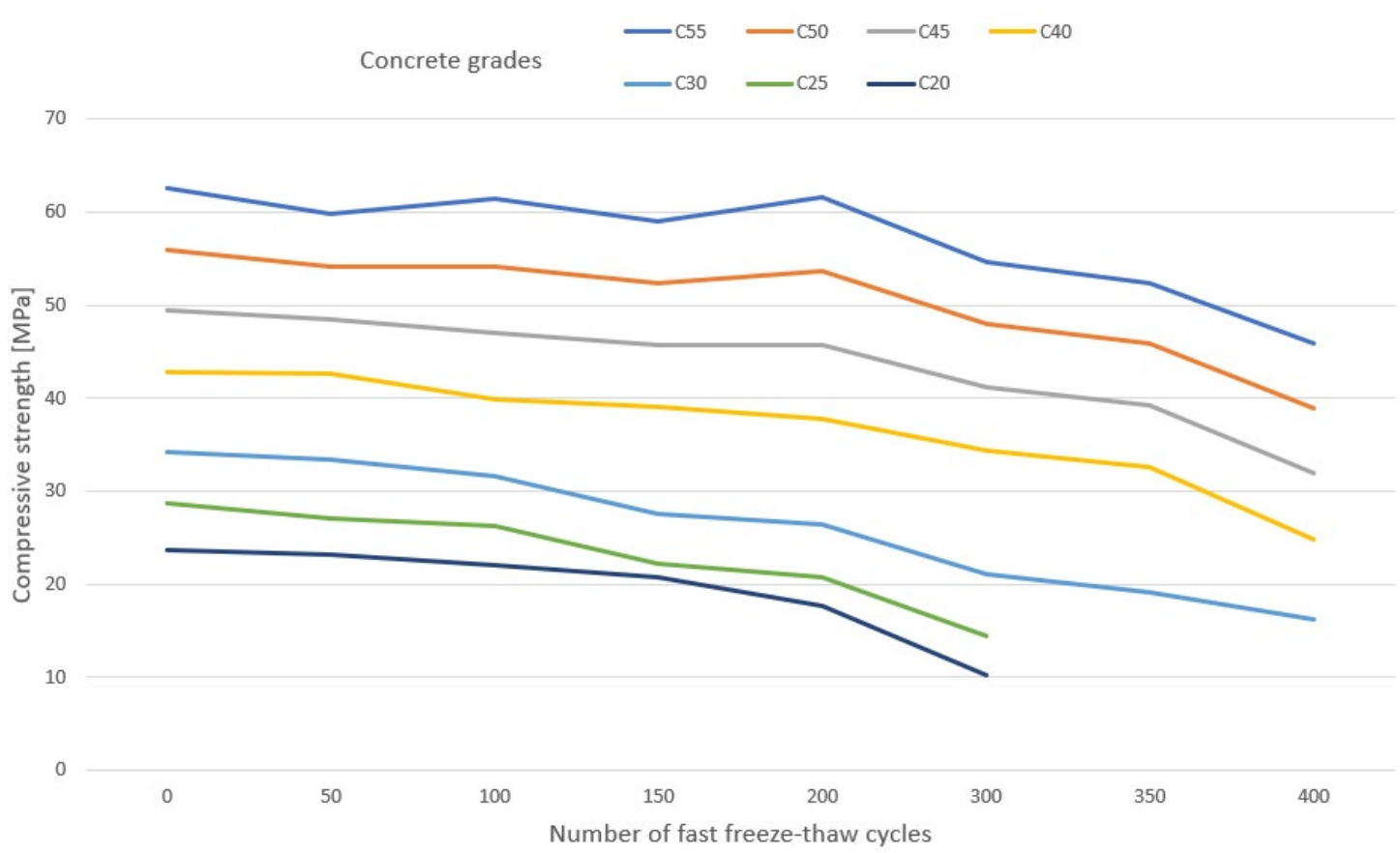

Figure 2 -Parameter N [26], added by interpolated and extrapolated values for concrete grades C45 and C55.

In the Shang et al.'s study, the loss of concrete strength has been calculated for concrete grades C20, C25, C30, C40 and C50. In the initial data of this article, concrete grades C45, C50 and C55 have been used, whereby the variable $N$ has been obtained for the concrete grades C45 and C55 by linear interpolation (C45) and extrapolation (C55). Interpolation can generally be considered fairly accurate, but extrapolated values include more uncertainties and should be treated with caution. However, the trends of the interpolated and extrapolated values are very similar to the ones in Shang et al.'s study.

From the Figure 2 it can be seen that the loss of strength is fairly linear for all, especially higher concrete grades, up to about 350 - 400 freeze-thaw cycles, after which the strengths start to fall at an accelerating rate. For this reason, the iteration has not been extended beyond 400 freeze-thaw cycles, although at higher strength grades, the strength has not yet dropped by the $30 \%$ represented by the model at that time. In this case, the calculated service lives obtained by the method are even greater than those presented in this article.

Instead, the Deterioration and service life prediction of concrete subjected to freeze-thaw cycles in the Na2SO4 solution method considers "only" the number of annual freeze-thaw cycles as well as the concrete grade. However, the first of these cannot be influenced, in which case the only factor that can be influenced is the concrete grade. The concrete grade itself does not take a position on whether the concrete is freeze-thaw resistant/air entrained or not, in which case the model is suitable for modeling freeze-thaw cracking only with air entrained concrete, in which case the air volume of the concrete does not have to be taken into account.

In addition, factor $B$ must be considered critically, as it has been set to 12 in a situation where the concrete is exposed to both freeze-thaw cycles and sulphate attack. Sulphate attack accelerates freeze-thaw degradation, so it might be possible to use higher value for that factor when sulphate attack in the actual structure can be found insignificant. However, sulphate attack is possible in the structures discussed in this article. 


\section{Factor method}

In factor method a lot of the criticality of the air volume is said by the fact that, for example, using $3 \%$ instead of $2 \%$ air volume in case pedestal 2 , the estimated service life of the pedestal increases from 78 to 1583 years. It can be concluded that the air entrained concrete is practically unbreakable calculated by the factor method, which is obviously not true.

On the other hand, in factor method, the factor $C$ (curing) is of great importance. But should a value of 1.0 or 0.7 be used for it? The old structure cannot verify the success of the initial curing. Admittedly, using a value of 0.7 (i.e., curing has failed) is on the safe side and potentially gives the structure a shorter service life than would be realistic. It should be noted, however, that special attention should be paid to curing in new structures, as it has a really large impact on the calculated service life of the structure. The calculated service life of a well-maintained structure increases.

The factor $E_{2}$ will be given values from 1.0 to 2.0 depending on the orientation of concrete structure. South and South-West directions have obviously smaller factor than North. According to studies on wind-driven rain (WDR) made on Finnish climate, amount of WDR is 3.54 times higher in south in coastal area and 2.88 times higher in southern Finland [25]. This is negligible in the case of pedestals but important in e.g. facades in block of flats.

The effect of inspection and maintenance (factor $G$ ) would also be of great importance if it were given a value of 1.0 instead of 0.7 . Inspection of concrete structure will not increase the freezethaw resistance of concrete. The pore structure of cast concrete does not change any better if somebody inspect it regularly. However, this must in fact also be counted on the safe side, as the structures in question are underground and thus cannot be serviced or inspected every 1 to 2 years.

\section{3}

\section{Requirements of methods}

The most important attributes considered in presented four different service life models are shown in Table 7. The attributes are quite different in those models. Freeze-thaw cycles belong directly or indirectly to all models, but everything else is different.

Table 7 - Attributes taken into account in different service life models.

\begin{tabular}{|c|c|c|c|c|c|c|}
\hline \multirow[b]{2}{*}{ Service life model } & \multicolumn{5}{|c|}{ Attributes taken into account } & \multirow[b]{2}{*}{$\begin{array}{l}\text { laboratory } \\
\text { tests needed }\end{array}$} \\
\hline & $\begin{array}{l}\text { concrete } \\
\text { grade }\end{array}$ & $\begin{array}{l}\mathrm{w} / \mathrm{c} \\
\text { ratio }\end{array}$ & $\begin{array}{l}\text { air } \\
\%\end{array}$ & $\begin{array}{c}\text { freeze-thaw } \\
\text { cycles }\end{array}$ & $\begin{array}{l}\text { exposure } \\
\text { class }\end{array}$ & \\
\hline Factor method & & $\mathrm{x}$ & $\mathrm{x}$ & $(\mathrm{x})^{*}$ & $\mathrm{x}$ & \\
\hline $\begin{array}{l}\text { Deterioration and service life prediction } \\
\text { of concrete subjected to freeze-thaw } \\
\text { cycles in } \mathrm{Na} 2 \mathrm{SO} 4 \text { solution method }\end{array}$ & $\mathrm{x}$ & & & $\mathrm{x}$ & & \\
\hline Fib 34 & $\mathrm{x}$ & & & $(\mathrm{x})^{*}$ & $\mathrm{x}$ & $\mathrm{x}$ \\
\hline $\begin{array}{l}\text { An equation for determining freeze- } \\
\text { thaw fatigue damage in concrete and a } \\
\text { model for predicting the service life }\end{array}$ & & & & $\mathrm{x}$ & & $\mathrm{x}$ \\
\hline
\end{tabular}


6.

\section{CONCLUSIONS}

The exact service life could be calculated only by the factor method and Deterioration and service life prediction of concrete subjected to freeze-thaw cycles in Na2SO4 Solution -method with the initial data. The other two methods presented are more theoretical and they require laboratory tests to obtain more information before the calculations can be properly executed. This article does not rank the methods. However, it can be said that the popularity of the coefficient method is certainly influenced by the fact that it is really practical and the estimated service life of an existing structure can be derived relatively easily, as the data needed for the calculation are readily available. Deterioration and service life Prediction of concrete subjected to freeze-thaw cycles in Na2SO4 Solution-method is also relatively easy to use, but the results obtained with it should be compared with the coefficient method carefully, as it has been made using different concretes used in Finland.

The factor method and Deterioration and service life prediction of concrete subjected to freezethaw cycles in Na2SO4 Solution -method gives quite different service lives for the same structure, if the number of used freeze-thaw cycles are close to those cycles where porewater freezes in concrete $\left(-5^{\circ} \mathrm{C}\right)$. In the case using average number of freeze-thaw cycles in the air $\left(0^{\circ} \mathrm{C}\right)$, the service lives are much closer each other's. However, porewater in concrete does not freeze immediately when air temperature goes below zero.

Air volume of concrete is the most critical factor in service life of concrete in outdoor climate. This can be seen in factor method where 1 per cent increase in air volume gives plenty of more service life. One of the oddest factors is inspection and maintenance, because the pore structure of concrete does not change whether the structure is maintained or not.

Damage to concrete due to freeze-thaw cracking is still poorly known and a sufficiently accurate service life model has not yet been developed for its computational modeling. Therefore, there is need to develop a service life model suitable for Finnish climate and concrete grades, which could be used for estimating the damage rate of an existing concrete structure. The model should be able to assess limit values, after which the structure repair method should be changed. As an example, a situation where the structure under consideration can still be repaired with a mortar patch repair. The new model could assess how many years from now this will no longer be possible but will require the application of heavier repair methods. A similar model already exists for estimating corrosion damage in reinforced concrete.

\section{ACKNOWLEDGMENT}

The authors wish to acknowledge Ramboll Finland Oy for received case-material.

\section{REFERENCES}

1. Lahdensivu J: "Durability Properties and Actual Deterioration of Finnish Concrete Façades and Balconies", PhD thesis, TUT Publ. 1028, Tampere University of Technology, 2012, 117 p.

2. Pakkala TA, Köliö A, Lahdensivu J \& Kiviste M: "Durability demands related to frost attack for Finnish concrete buildings in changing climate", Building and Environment, Vol 82, No. December 2014, pp. 27-41.

3. Jylhä K, Ruosteenoja K, Räisänen J, Venäläinen A, Tuomenvirta H, Ruokolainen L, Saku S \& 
Seitola T: "The changing climate in Finland: estimates for adaptation studies" ("Suomen muuttuva ilmasto: arvioita ja sopeutumistutkimuksia"), ACCLIM-project report 2009. Finnish Meteorological Institute, Reports 4, 2009, 102 pp. (In Finnish).

4. Kuosa H \& Vesikari E: "Ensuring of concrete frost resistance Part 1: Basic data and service life design" ("Betonin pakkasenkestävyyden varmistaminen Osa 1: perusteet ja käyttöikäsuunnittelu”), VTT Technical Research Centre of Finland, Research notes 2056, 2000, 141 p. (in Finnish)

5. Fagerlund G: "The critical degree of saturation method of assessing the freeze/thaw resistance of concrete", Tentative RILEM recommendation. Prepared on behalf of RILEM Committee 4 CDC. Materiaux et Constructions, Vol. 58, 1977, pp. 217-229.

6. Pigeon M \& Pleau R: "Durability of concrete in cold climates", Suffolk, E \& FN Spon, 1995, $244 \mathrm{pp}$.

7. Penttala V: "Freezing-induced strains and pressures in wet porous materials and especially in concrete mortars", Advanced Cement Based Materials, Vol. 7, 1998, pp. 8-19.

8. Hedlund H, Jonasson J-E: "Effect on stress development of restrained thermal and moisture deformation" In: Baroghel-Bouny V, Aïticin P-C, editors. Shrinkage of concrete, shrinkage 2000. CachanCedex. RILEM proceedings PRO17, 2000, pp. 355 - 377.

9. Mäkinen K: "Strength and physical properties of materials", Builders calendar 2011, Rakennustieto Oy, Hämeenlinna, 2010, pp. 375 - 378

10. Neville AM: "Properties of concrete", Longman Group Limited, Essex, England, 1995, 844 p.

11. Sarja A \& Vesikari E (Ed.): "Durability Design of Concrete Structures", Report of RILEM Technical Committee TC 130-CSL, RILEM, 1996, 165 pp.

12. FIB, "Model Code for Service Life Design", Bulletin 34, FIB, 2006, 206 pp.

13. Kuosa H, Ferreira RM, Holt E, Leivo M \& Vesikari E: "Effect of coupled deterioration by freeze-thaw, carbonation and chlorides on concrete service life", Cement and Concrete Composites, Vol. 47, 2014, pp. 32-40.

14. Ferreira R M, Kuosa H \& Makkonen L: "Performance \& Durability of Concrete in Extreme Cold Environment", CSLA Project - Task 1. Literature Review, VTT-R-073643-12, VTT, 2012.

15. Fagerlund G: "On the service life of concrete exposed to frost action", "Freeze-Thaw Durability of Concrete" (Edited by Marchand J, Pigeon M. \& Setzer, M.), 1997, pp. 21-41.

16. Bager D H \& Jacobsen S: "A conceptual model for the freeze-thaw damage of concrete" Proceedings, 3rd Nordic Research Seminar Frost resistance of building materials, 1999, pp. 118.

17. Fagerlund G: "A service life model for internal frost damage in concrete", Division for Building Material, Lund Institute of Technology, TVBM-3119, 2004, 136 p.

18. Scherer G \& Valenza J: "Mechanisms of Frost Damage", Proceedings, "Materials Science of Concrete", American Ceramic Society, Vol. 7, 2005, pp. 209-246.

19. Vesikari E, Kuosa H, Piironen J \& Ferreira RM: "Modelling synergistic effects of carbonation/chloride penetration and frost attack for service life design of concrete bridges", Proceedings, IABMAS, 2012, pp. 3297-3933.

20. Finnish Concrete Association, "Concrete Codes - by65", 2016, 164 pp. (In Finnish)

21. ISO 15686-1: Buildings and constructed assets - Service life planning, 2011

22. De Brito J, Silva A: "Report prepared by CIB W080 - Prediction of service life of building materials \& components", Instituto Superior Tecnico, University of Lisbon, 2021, 83 pp.

23. Köliö A: "Propagation of Carbonation Induced Reinforcement Corrosion in Existing Concrete Facades Exposed to the Finnish Climate", PhD thesis, TUT Publ. 1399, Tampere University of Technology, 2016, 147 pp.

24. Li G, Wang D \& Du J: "Deterioration and Service Life Prediction of Concrete Subjected to Freeze-Thaw Cycles in Na2SO4 Solution", American Journal of Civil Engineering, Vol. 4, issue 3, 2016, $104-110 \mathrm{pp}$. 
25. Pakkala TA, Lemberg AM, Lahdensivu J \& Pentti M: "Climate change effect on wind-driven rain on facades", Nordic Concrete Research, No. 54, 2016, pp. 31-49.

26. Shang H, Cao W \& Wang B: "Effect of Fast Freeze-Thaw Cycles on Mechanical Properties of Ordinary-Air-Entrained Concrete", The Scientific World Journal, 2014, 7 pp.

27. Leivo M: "Ensuring freeze-thaw resistance of concrete, part 2. Quality control and quality assurance" ("Betonin pakkasenkestävyyden varmistaminen, Osa 2. Laadunvalvonta ja varmistus"), Valtion teknillinen tutkimuskeskus (VTT), 2000, 38 pp. (In Finnish)

28. Lahdensivu J \& Aromaa, J: "Repair of alkali aggregate reaction damaged swimming pool", Case Studies in Construction Materials, Vol. 3, 2015, pp. 1-8.

29. Schiess1 P, Bamforth P, Baroghel-Bouny V, Corley G, Faber M, Forbes J, Gehlen C, Helene P, Helland S, Ishida T, Markeset G, Nilsson L, Rostam S, Siemes A \& Walraven J: "Model Code for Service Life Design", International Federation for Structural Concrete (fib), 2006, 116 p.

30. $\mathrm{Yu} \mathrm{H}, \mathrm{Ma} \mathrm{H} \& \mathrm{Yan} \mathrm{K}$ : "An equation for determining freeze-thaw fatigue damage in concrete and a model for predicting the service life", Construction and building materials. Vol. 137, 2017, $104-116 \mathrm{p}$.

31. Finnish Standard Association, SFS 5447: "Concrete. Durability. Freeze-thaw resistance", Finland, 1988, 318 pp. (In Finnish). 